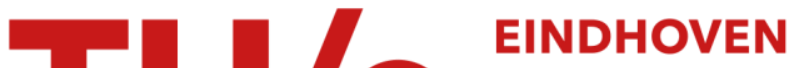 UNIVERSITY OF TECHNOLOGY
}

\section{Managing patents in standardization : lessons from ETSI's handling of UMTS}

Citation for published version (APA):

Bekkers, R. N. A., \& West, J. (2007). Managing patents in standardization : lessons from ETSI's handling of UMTS. In 5th International Conference on Standardization and Innovation in Information Technology (SIIT), October 17-19, 2007 (pp. 155-170). University of Calgary. https://doi.org/10.1109/SIIT.2007.4629326

DOI:

10.1109/SIIT.2007.4629326

Document status and date:

Published: 01/01/2007

\section{Document Version:}

Publisher's PDF, also known as Version of Record (includes final page, issue and volume numbers)

\section{Please check the document version of this publication:}

- A submitted manuscript is the version of the article upon submission and before peer-review. There can be important differences between the submitted version and the official published version of record. People interested in the research are advised to contact the author for the final version of the publication, or visit the $\mathrm{DOI}$ to the publisher's website.

- The final author version and the galley proof are versions of the publication after peer review.

- The final published version features the final layout of the paper including the volume, issue and page numbers.

Link to publication

\section{General rights}

Copyright and moral rights for the publications made accessible in the public portal are retained by the authors and/or other copyright owners and it is a condition of accessing publications that users recognise and abide by the legal requirements associated with these rights.

- Users may download and print one copy of any publication from the public portal for the purpose of private study or research.

- You may not further distribute the material or use it for any profit-making activity or commercial gain

- You may freely distribute the URL identifying the publication in the public portal.

If the publication is distributed under the terms of Article 25fa of the Dutch Copyright Act, indicated by the "Taverne" license above, please follow below link for the End User Agreement:

www.tue.nl/taverne

Take down policy

If you believe that this document breaches copyright please contact us at:

openaccess@tue.nl

providing details and we will investigate your claim. 


\title{
MANAging PATENTS in Standardization: LESSONS FROM ETSI'S HANDLING OF UMTS
}

\author{
Rudi Bekkers \\ TECHNISCHE UNIVERSITEIT EINDHOVEN
}

\author{
Joel West \\ SAN JOSÉ STATE UNIVERSITY
}

\begin{abstract}
The impact of patents and patent royalties are a major concern of standards setting organisations. Here we examine the patents filed in the UMTS $3 \mathrm{rd}$ generation mobile phone standard, governed by the ETSI IPR policy in response to patent issues faced during the earlier GSM standardization. We contrast firm strategies and policy effectiveness between the GSM and UMTS efforts, and review the potential impact of potential changes to the ETSI IPR policy.
\end{abstract}

\section{Introduction}

$\mathrm{T}$ he management of patent royalties has become one of the most problematic and contentious areas of multivendor ICT standardization efforts. While standards setting organizations (SSOs) are organized around a presumption of cooperation toward a shared goal, the increasing role of patents in standards has also increased the divergence of stakeholder interests in standardization, particularly between producers and users of standardized products. Although some SSOs have sought to manage standards-related patents or even ban them entirely, other SSOs seem to be in denial; all three approaches have serious limitations.

In this study, we examine the nature and role of patents in one of the largest ICT standardization efforts of the past decade, that of the Universal Mobile Telecommunications System (UMTS), a 3rd generation mobile telephone standard. This standardization effort was governed by the IPR (intellectual property rights) policy developed in response to the difficulties faced handling patents during GSM standardization.

We are interested in addressing three questions. First, how did the IPR strategies used for UMTS compared to those used for GSM? How well did the policies work this time? And what SSO policies might be used in the future?

We first review the standardization history and IPR policies for GSM and UMTS. We then analyze the 1,227 unique patents claimed to be essential by 72 firms involved in the UMTS standardization effort. We then discuss the problems with the UMTS patent policy, and a series of changes proposed both inside and outside the standardization effort, and conclude with a summary of the study's contributions.

\section{ETSI Standardization \& IPR Policy}

The standardization of UMTS ${ }^{1}$ was both technically and institutionally a successor to that of the 2nd generation GSM (née Group Special Mobile). Much of the technical development took place at the European Telecommunications Standards Institute (ETSI), an outgrowth of the GSM standardization effort, and it involved many of the same telecommunications vendors and operators that led the early GSM effort.

In particular, the UMTS standardization began with the IPR policy created by ETSI in response to problems encountered during GSM standardization. Here we review those problems, the ETSI policy that resulted, and how they were applied during UMTS standardization.

GSM standardization

The initiative to create the first pan-European mobile phone standard began with the Conférence Européenne des Administrations des Postes et des Télécommunications (CEPT), the organisation of all the major incumbent

UMTS has also been called Wideband CDMA (W-CDMA), DS-CDMA and later 3GSM. For consistency's sake, throughout this paper we use the original UMTS name. 
telephone operators. Under pressure from the European commission, in 1988 the standardization efforts were transferred to the newly-created ETSI, but with the operators still in control of standards deployment through a group called the GSM Memorandum of Understanding (MoU) (Bekkers, 2001).

As an initial IPR policy, the GSM MoU proposed a requirement that suppliers must grant operators a free worldwide license for all patents they held to implement GSM, and indemnify operators for all claims of patent infringement by third parties. However, the patent licensing policy was rejected by one of the largest IPR holders, Motorola, which was locked out of the U.S. market and faced high barriers from incumbent suppliers in the European market. Other manufacturers tacitly supported the Motorola stance, leading to its defeat (Garrard, 1998; Iversen, 1999).

In response, most (but not all) operators substituted a requirement that all suppliers promise to provide IPR to the entire GSM community (both suppliers and operators) under 'fair, reasonable and non-discriminatory conditions' (Bekkers et al, 2002: 179). In some cases, this FRAND clause was obtained by additional payments to suppliers.

Motorola agreed to these terms under limited conditions, and obtained only a handful of supply contracts. At the same time, it refused to license its IPR under royalty, but instead required cross licensing, eventually negotiating licenses with Siemens, Alcatel, Nokia and Ericsson (Garrard, 1998; Bekkers et al, 2002). These crosslicensing agreements provided a strong cost advantage for the five incumbent licensees, and created high barriers to entry by prospective GSM suppliers, with royalty rates for non-cross-licensees estimated at 10-13\% (West, 2006).

\section{Development of ETSI's IPR policy}

After the rejection of the GSM MoU policy, ETSI made several attempts to develop its own IPR policy. Under heavy influence of operators, in 1993 ETSI proposed an IPR policy that firms were assumed to license IPR on a non-exclusive, FRAND basis unless they notify ETSI otherwise. Again this policy was abandoned in the face of informal and legal opposition (Iversen, 1999; Bekkers, 2001). In 1994, ETSI proposed what became its eventual policy, the so-called (F)RAND model that has been adopted by most formal standards bodies around the world. In brief, the 1994 ETSI IPR policy (which remains largely unchanged) is: ${ }^{2}$

- Holders of IPR, member or not, will be rewarded in a suitable and fair manner;

- Members will make a reasonable effort to inform ETSI of IPRs they are aware of. If they propose a technical design to ETSI they will also, in good faith, draw attention to IPRs that could become essential if that proposal is adopted;

- If an essential IPR is identified, the director of ETSI will request its holder, member or not, to make licenses available under fair, reasonable and non-discriminating terms (RAND);

- $\quad$ ETSI members can choose not to license an IPR. If no other alternatives exist, the director of ETSI will request the holder to revise its position. If a member refuses to do so, it has to inform the director about its reasons; this explanation will be passed on to ETSI's advisors (which include the European Commission). If no solution is found, ETSI may eventually halt the work on the standard or look for other technical alternatives that would not infringe upon the technology in question.

- To enable these policies, during each meeting of an ETSI Technical Committee (TC), the participants are reminded that they should disclose possible IPR on the technical solutions that are being discussed.

Despite the apparent simplicity of the RAND guidelines, the interaction of firm and SSO activities related to patents and standardization remain complex. The interdependence of these activities with each other and the relevant SSO policies are illustrated by

Within this framework, we can observe various firm strategies for IPR and standards — both for the members of an SSO and for third parties. Overall, member firms have the choice to participate in the TCs that draft standards and contribute knowledge and technology to that process (1). Those that participate often attempt to influence the prospective standard towards certain technologies, particularly those covered by their own IPR (2). They may also decide to develop and patent technologies responding to what they see that is happening in the standardization process (anticipative patenting; 3). The SSO's IPR policy often stipulate that participants disclose any IPR they are aware of (including their own) during the meetings of such committees $(4,5)$.

In some cases, the work in these SSO committees is preceded by earlier R\&D efforts, as when the UMTS standard was derived from earlier R\&D collaborations sponsored by the EU framework programs. In principle, we can have the same interaction processes in such research efforts $(6,7$ and 8$)$. At one point in time, formal decisions

These principles remain in the ETSI Rules of Procedures as published in November 2006 (ETSI, 2006). 
are made on draft and final standards. Members learn these decisions by the exact content of the deliverables of the SSOs (9). ${ }^{3}$ Once the standards are ratified, under the ETSI policy member firms are required to notify the SSO of the essential IPR they hold for some specific part of that standard. Firms may (or may not) meet the obligation to notify and may (or may not) declare that they will license this IPR on the basis of RAND conditions (10). Finally, firms will negotiate and set their licensing conditions for any licensees (11).

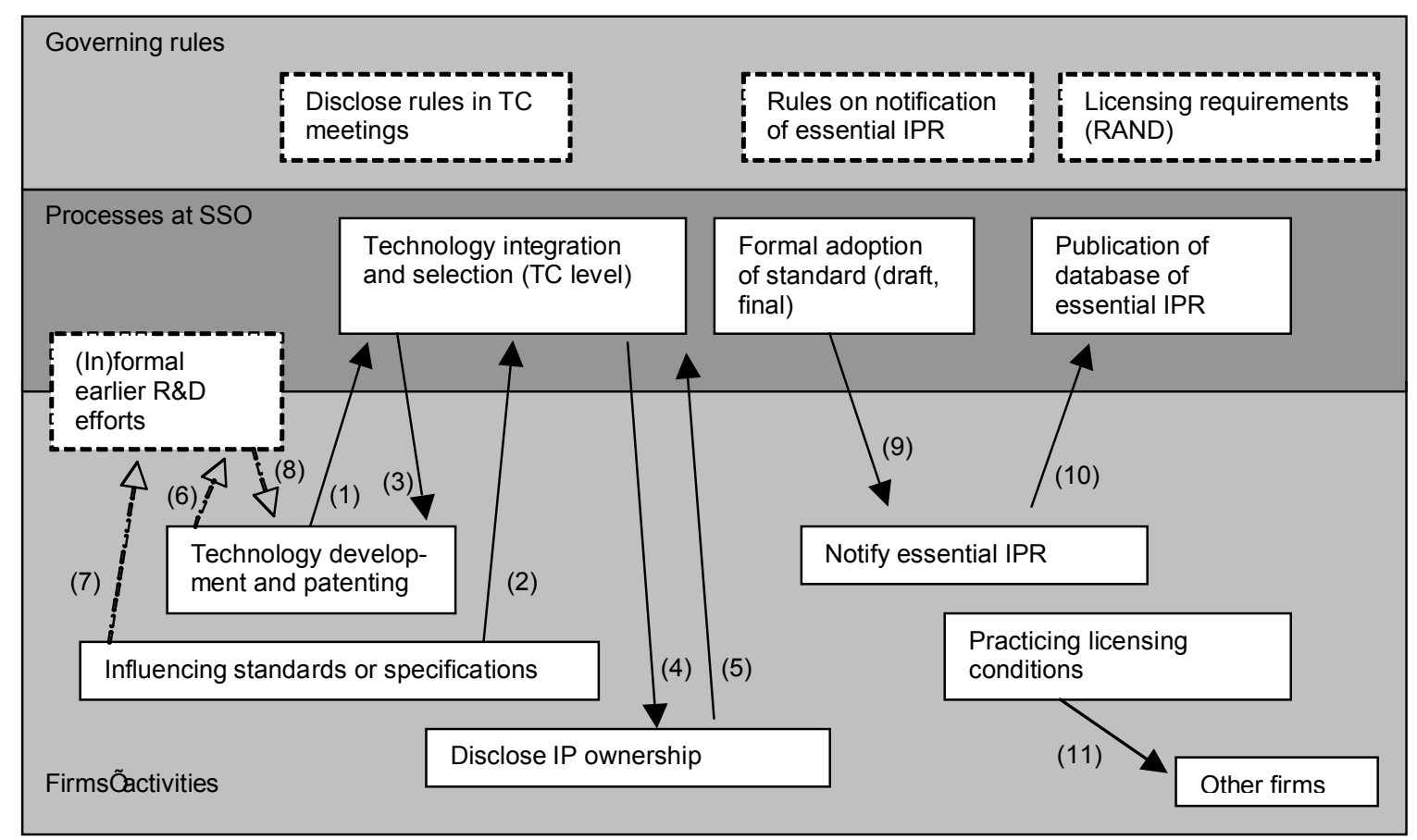

Figure 1: Relationship of technical processes, IPR processes and firm behaviour

\section{UMTS standardization}

UMTS standardization progressed in three important phases: exploratory research, formal standardization and standard implementation/refinement (Table 1). ${ }^{4}$

\begin{tabular}{|c|c|c|c|}
\hline Phase & Time frame & Main activities & Landmark event concluding this period \\
\hline $\begin{array}{l}\text { 1. Early research } \\
\text { into } 3 \mathrm{G}\end{array}$ & $\begin{array}{l}\text { Around } 1990 \text { to } \\
\text { early } 1995\end{array}$ & - Explorative R\&D only & $\begin{array}{l}\text { RACE research program output shows } \\
\text { outline of UMTS technology (though no } \\
\text { specific choices yet made) }\end{array}$ \\
\hline $\begin{array}{l}\text { 2. Drafting the } \\
\text { UMTS standard and } \\
\text { worldwide } \\
\text { alignment }\end{array}$ & $\begin{array}{l}\text { Early } 1995 \text { to } \\
\text { late } 1999\end{array}$ & $\begin{array}{l}\text { - R\&D } \\
\text { - EU induces establishment of } \\
\text { UMTS Task Force and } \\
\text { UMTS Forum } \\
\text { - Japan takes over the lead } \\
\text { - Renewal European interest and } \\
\text { UMTS technology choice } \\
\text { - Worldwide alignment }\end{array}$ & $\begin{array}{l}\text { The so-called Release } 99 \text { version of the } \\
\text { standard is the full, first stable version and } \\
\text { allows developers to design actual } \\
\text { equipment }\end{array}$ \\
\hline $\begin{array}{l}\text { 3. Implementation } \\
\text { and further } \\
\text { development of the } \\
\text { standard }\end{array}$ & From late 1999 & $\begin{array}{l}\text { - Improving and refining the } \\
\text { UMTS standard } \\
\text { - License auctions } \\
\text { - Product development and } \\
\text { network procurement }\end{array}$ & $\mathrm{n} / \mathrm{a}$ \\
\hline
\end{tabular}

Table 1: UMTS development phases

3 SSOs differ considerably in their voting processes, which can include voting by individual member, firm, or national delegation.

4 The complete details of the UMTS standardization are beyond the scope of this paper. This summary is adapted from Bekkers (2001) and Hillebrand (2003). 
Phase 1: Exploratory Research. The first activities related to UMTS began in 1990, prior to the launch of GSM. While the specific goals and technologies were not yet specified, there was a presumption that the 3rd generation standard would support mobile applications beyond just voice.

The earliest investigation was aided by R\&D funding from the European Union. In particular, the 2nd Research and Development in Advanced Communications Technologies for Europe (RACE) program from 19921995 included specific grants for mobile phone technologies, one focused on CDMA and the other on extending an advanced TDMA technology developed during RACE-1 (1988-1992).

At the end of RACE-2, there was an effort to select one of the two competing technologies as the basis for UMTS, but the competition found no clear winner (Buitenwerf, 1994). While the program did not pick a specific technology, RACE-2 suggested eventual performance characteristics and also signaled to those outside RACE that development of a 3 rd generation mobile standard had begun. However, the $3 \mathrm{G}$ developments were largely ignored by GSM operators, who were focusing on increasing subscribers of their existing 2G systems (Garrard, 1998, p. 478).

Phase 2: Drafting a Standard. Around 1995, more firms joined European UMTS standardization efforts. The EU budgeted 100 million ECU to FRAMES (Future Radio Wideband Multiple Access Systems), and contracts were won by Ericsson, Nokia, Siemens, France Telecom and various European universities. The EU also established a UMTS task force in 1995.

In 1996, Japan's Ministry of Post and Telecommunications (MPT) set up a group to study Japan's contribution to $3 \mathrm{G}$ standardization, including domestic operators, manufacturers, and key European, US and Korean manufacturers. Even before the group picked a technology, NTT DoCoMo placed an order with ten vendors for an experimental third-generation network, and announced a very aggressive further roll-out scheme. Doing this, NTT DoCoMo confronted other Japanese actors with a fait accompli. ARIB (Association of Radio Industries and Businesses) - a Japanese SSO - adopted the NTT choice and assumed further responsibility for developing the standard.

The Japanese activity accelerated European development of UMTS. As the official European telecommunication standards body, ETSI claimed the role to complete the UMTS standard. However, the European vendors split on which of the two RACE-2 derived technologies should become the standard: Nokia and Ericsson favored the wideband CDMA technology they had delivered as an experimental system for DoCoMo, while Alcatel and Siemens argued for a time-division TD/CDMA. After ETSI members were unable to pick a standard in 19971998, a compromise combining UMTS with elements of TD/CDMA was selected. This technology was soon endorsed by Japanese industry, and later ETSI and ARIB jointly founded the 3GPP (3rd Generation Partnership Project), which would eventually assume responsibility for UMTS standardization.

The UMTS standardization was delayed by an IPR fight between European vendors (particularly Ericsson) and Qualcomm, which owned dozens of CDMA patents believed relevant to the UMTS technology. Qualcomm was promoting a rival $3 \mathrm{G}$ standard (cdma2000) through a rival SSO (3GPP2), and sought changes to the UMTS specifications to make it easier to develop components that would support both $3 \mathrm{G}$ technologies. A group of operators eventually forced the parties to harmonize their specifications in 1999.

By the end of 1999, 3GPP completed the first complete draft of the specification, UMTS Phase 1, also known as 'Release 99.' This defined the core of the UMTS standard, allowing vendors to develop products and operators to procure networks.

Phase 3: Implementation and Refinement. Beginning in 2000, European countries began to allocate UMTS licenses using two approaches, either 'beauty contest' (government selection based on nominal merit) or an auction (highest price). In the latter case, the cost of licenses raises doubts about whether UMTS would ever be economically deployed.

Since the Release 99 standard, 3GPP and its member SSOs have produced additional versions of the UMTS standard. One area of greatest activity was in increasing data transmission rates, including the HSDPA and HSUPA extensions.

\section{An Analysis of UMTS Patents}

To understand the UMTS IPR situation - and to enable comparison to that of GSM - this section analyzes the patent ownership for UMTS. Our data were compiled from UMTS standards-related patent declarations, cross referenced to other patent sources and databases.

The list of possible patents officially claimed essential for implementing UMTS can be obtained by studying the appropriate printed and online documents at the various standards bodies that participate in 3GPP: 
ARIB from Japan, ATIS from the U.S., CCSA from China, ETSI from Europe and TTA from Korea. Many of these firms made GSM-related declarations, since most UMTS infrastructure and terminal equipment provide backward compatibility for GSM and thus are affected by such IPR. The firms adopt a variety of patent declaration policies, which may be partly explained by the fact that firms are not always member of all these standard bodies. A total of 72 firms claimed to own essential IPR either for the UMTS or the GSM standard. Consequently, a firm producing UMTS equipment (terminals or infrastructure) would, in principle, need a license from each of the 52 firms claiming UMTS IPR. ${ }^{5}$ It would need the patents from the 20 GSM-only firms if their products are to be backward compatible with GSM (a commercial requirement for the European market).

In addition to these patent disclosures, our primary dataset included the actual UMTS patents themselves, as filed in multiple jurisdictions. Unfortunately, not all the sources are complete or consistent enough to allow for a detailed analysis. Therefore our following analysis does not consider the patents for all the firms, but only those patents disclosed through the most reliable dataset available. This 2,427 page report (ETSI 2005) lists a total of 13,106 patent notifications. We use the 6,313 patents (from 37 firms) relating to UMTS, and not those relating to other ETSI standards such as TETRA and ERMES; for this analysis, GSM patents are included only if they are notified as claimed to relate to the UMTS standard.

However, there is the possibility of double counting if an IPR holder applies for different patents on the same innovation in different jurisdictions. There may also be registrations at the European Patent Office (EPO) or by the World Intellectual Property Organization (commonly known as PCT patents, and designated by the prefix 'WO'). Also, the same innovation may be listed more than once, at different ETSI projects (all covering UMTS). Such double counts have been removed using the patent application number and the patent numbers. To translate such these numbers from their various filing jurisdictions, we used a variety of sources, including the EPO's MIMOSA patent database. The patent citation dataset developed by OECD proved to be particularly useful for identifying equivalent patents, even though it was originally designed for another purpose. Its main drawback, however, is that it only includes (granted) patents with application dates up to the year 2001.

We also used several online patent data sources, most notable the Esp@ce service of the EPO and the patent search services of the U.S. Patent Office (USPTO), the WIPO, and those of the Japanese Patent office. The data reduction is not a trivial task, since identical patents may be notified using totally different names while sometimes different patents do share the same name. Also, the data provided are often incomplete, inconsistently coded and contains numerous typographic errors (both in their titles and their numbers). We included all the notified patents, regardless whether they were already granted or still pending.

Altogether, we were able to reduce the 6,313 UMTS patents from ETSI (2005) to 1,227 unique, essential patents, of which 801 patents were filed at the EPO (see Table 2). For those patents that were not filed under the EPO, we tried to find the U.S. or PCT patent numbers, which we found for 276 and 104 patents, respectively. The remaining 24 patent notifications were so incomplete that we were not able to identify them.

\begin{tabular}{ll}
\hline Patent identification & \multicolumn{1}{c}{$\begin{array}{c}\text { Claimed number of unique } \\
\text { essential patents }\end{array}$} \\
\hline EPO & 801 \\
US, no EPO & 276 \\
PCT/WO, no EPO & 104 \\
Japan, no EPO & 8 \\
Canada (no EPO, US or PCT) & 5 \\
Germany, Finnish, French, English, Danish or & 9 \\
$\quad$ Norwegian patent only (no EPO, US or PCT) & \\
Unidentified & 24 \\
Total & 1227 \\
\hline
\end{tabular}

Source: own analysis of ETSI (2005)

Table 2: Patents by identifying patent treaty or country

Table 3 provides an overview of the number of unique patents for the 37 firms listed in ETSI (2005). Nokia, Ericsson, Qualcomm and InterDigital Communications hold the largest patent portfolios, followed by eight

There might be different IPR claims for different approaches to implementing an essential feature of a standard, in which case the firm would need to license only one approach. 
firms that own between 15 and 86 patents each; the remaining 20 firms have notified five patents or fewer. Several of these patent portfolios reflected changes in corporate structure during the period 1980-2000, as when AT\&T spinoff Lucent assumed patent licensing rights from AT\&T (with its 6 GSM patents). Other examples included Qualcomm's acquisition of SnapTrack (and its patents), the InterDigital acquisitions of SCS Mobilecom, and Nokia's purchase of the patent rights of the University of Sherbrooke. A few individuals account for a significant fraction of these patents, particularly Donald Schilling of InterDigital (225 EPO patents) and Klein Gilhousen (312) and Paul Jacobs (220) of Qualcomm. ${ }^{6}$

Most firms in our source have provided detailed patent notifications, though six firms note that they believe they own essential patents without specifying the number of patents or their details; there is no way to tell if these firms have one relevant patent or 50. We refer to these statements as 'blanket claims,' but the vague nature of these claims makes it impossible to perform some analyzes for these firms.

\begin{tabular}{ll}
\hline Firm & $\begin{array}{l}\text { Claimed number of } \\
\text { unique essential patents }\end{array}$ \\
\hline Nokia & 248 \\
Ericsson & 244 \\
Qualcomm & 228 \\
InterDigital & 168 \\
Samsung & 86 \\
Motorola & 54 \\
Philips & 45 \\
Siemens & 38 \\
Asustek & 23 \\
Alcatel & 20 \\
Mitsubishi & 18 \\
Nortel & 15 \\
Toshiba, ETRI, Voiceage, France Telecom, Evolium, Sun & Each claiming 5 or less \\
$\quad$ Microsystems, OKI, Tantivy Communications, IPR Licensing, & patents \\
$\quad$ Salbu Research \& Development, Cisco Systems, Robert Bosch, & \\
$\quad$ Canon, CCL/ITRI, Media Farm, Aepona, Bijitec, Wi-Lan, Telia & \\
Coding Technologies, Italtel, Lucent, NEC, Omnipoint, Texas & Blanket claim \\
$\quad$ Instruments & \\
\hline Source: ETSI (2005). Firms in italics agreed to license via W-CDMA Patent Licensing Program (cf. PlatformWCDMA 2004) \\
$\quad$ Table 3: ETSI notified essential patents by firm
\end{tabular}

\section{IPR impact on firms implementing UMTS}

In total, 72 firms claim to hold IPRs essential to either UMTS or GSM. This count would be overstated for firms that exaggerated the extent of the IPR, and understated to the degree that firms fail to notify essential patents. Firms that are not ETSI members may choose to not disclose their IPR, because non-member firms cannot be compelled by UMTS standardization bodies to disclose patents, suggesting there might be additional firms beyond the 72 that identified their IPR. ${ }^{7}$

The large number of 'essential' patent holders suggests that gaining IPR clearance to build UMTScompliant hardware would be a complex and time-consuming processes, with potentially some 5,000 bilateral agreements possible among this group. Even more licenses would be required if non-IPR holders were interested in

6 Schilling was the founder of SCS Mobilecom, acquired in the 1992 merger which created InterDigital. Gilhousen was one of the cofounders of Qualcomm, while Jacobs was the son of Qualcomm's first CEO who himself became CEO in 2005.

7 Based on a sampling of a single patent from 887 patent families of the 3GPP and 3GPP2, Goodman \& Myers (2005) estimated that only $21 \%$ of the overall $3 \mathrm{G}$ patents were essential, while a British consultancy claimed (without verifiable evidence) that as a few as $10 \%$ of the patents are "crucial" to implement 3G (PA Consulting 2002). Because we cannot identify which patents are exaggerated or missing, we have chosen to conduct our analysis using the nominal disclosures, adjusted for double-counting as noted above. 
producing products. This might include existing GSM phone makers HP, Palm, Sagem, Research in Motion, as well as makers of PDAs, cellular modems, or other products.

One possible solution to such high transactions costs would be the formation of a patent pool, allowing a manufacturer to execute many less than the 72 firm licenses. Work on a UMTS pool entitled 3G Patent Platform started as early as 1998. After receiving positive business review letters from the US Department of Justice and the equivalent European and Japanese competition authorities in 2002, the pool established a joint licensing program in 2004 (PlatformWCDMA 2004). The pool currently includes only 7 of the 72 firms, and only 1 of the 10 largest patent holders. As measured by either firms or patents covered, the pool would appear to have a fairly minimal impact on the patenting costs.

Finally, it is important to note that also patents that do not seem to be essential to a standard can be very valuable and other manufacturers will feel the need to license those. These patents cover features that are considered valuable by customers (such as the T9 text entry technology for SMS services), or cover technologies that improve the performance of devices or lower their costs, but are not strictly essential if there are other (possibly more expensive implementations) that also conform to the standard. These non-essential patents may be owned by firms that hold essential IPRs, or by other firms.

All in all, we conclude that a considerable number of different firms or organizations hold IPR essential to either GSM or UMTS, and both the number of firms and patents are much higher than they were for GSM. For a fair comparison, we look at both standards six years for the standard was frozen (for GSM that was the phase-1 standard, for UMTS the Release-99). This means that the patent portfolios we compare both include the patents essential to the first version, and those essential to later improvements or enhancements added to the official standard. For GSM, six years after the first stable specification, there were a total of 23 essential patent holders and a total of 140 essential patents. With UMTS, also six years after the first stable specification, we found 72 essential patent holders and a total of 1,227 essential patents, an eightfold increase.

\section{Differences in firm patent strategies}

There are a number of important differences between firms in their patent motivations and output. Below, we will discuss three specific aspects that reflect firm strategy:

1. Patent timing (with regards to the standard-setting process)

2. Targeting (towards the standards'content)

3. Technological diversity of the firm's essential patent portfolio 


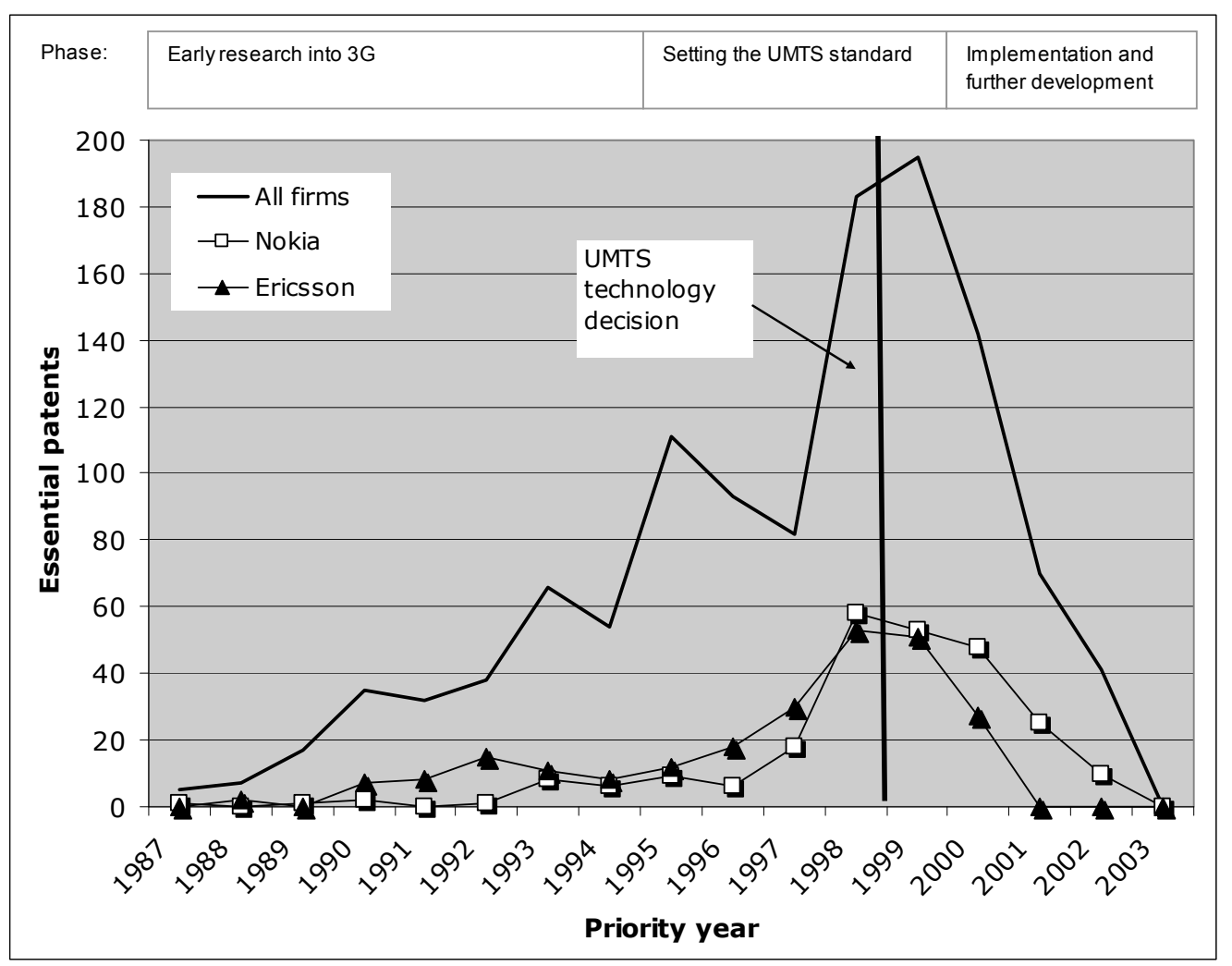

Figure 1: Timing of essential UMTS patents by leading manufacturers

Timing. A key form of standards-related strategic patenting is when a firm deduces the direction that a standardization effort is proceeding and then attempts to create patents to read on that standard. One way such strategic patenting might be evidenced would be if the patents were filed well after the corresponding standardization effort had begun. We analyzed the (earliest) priority dates of the 1203 patents we were able to identify (see Figure 1). More than the patent grant dates, these dates reflect the point in time at which the technology that is covered by the patent has been developed. These priority dates range from 1982 to 2002 . There is a clear surge of patenting activities starting from 1990, with a peak in 1998-1999.

In addition to the all patents, Figure 1 shows separate lines for the priority date for the patents held by Nokia and Ericsson. Both firms have rather identical patterns: there is a clear peak in patenting activity in the years 1998 and 1999, exactly the period in which the basic technology choice was made. Both firms were designing their (successful) proposal for that choice, and then involved in crafting the details of the standard within the relevant ETSI Technical Committees.

Interestingly enough, Qualcomm and InterDigital, the two other large IPR holders, show rather different timing patterns (see Figure 2). For Qualcomm, 199 of its 226 claimed essential patents were applied for in 1996 or earlier. That is years before the basic technology for UMTS was selected (in 1999). Although there is usually some delay between the priority date and the moment other parties can see the claims, when the UMTS technology was selected it was quite clear that Qualcomm owned an extensive portfolio of relevant patents. Also, Qualcomm was not involved in any of the proposals to ETSI (focusing on its competing cdma2000 technology instead) and was relatively absent when the standard was further set and drafted. For the firm InterDigital, we also see that many patents were applied for long before the 1999 technology choice, though this company also shows more patenting activities in 2000 and 2001. 


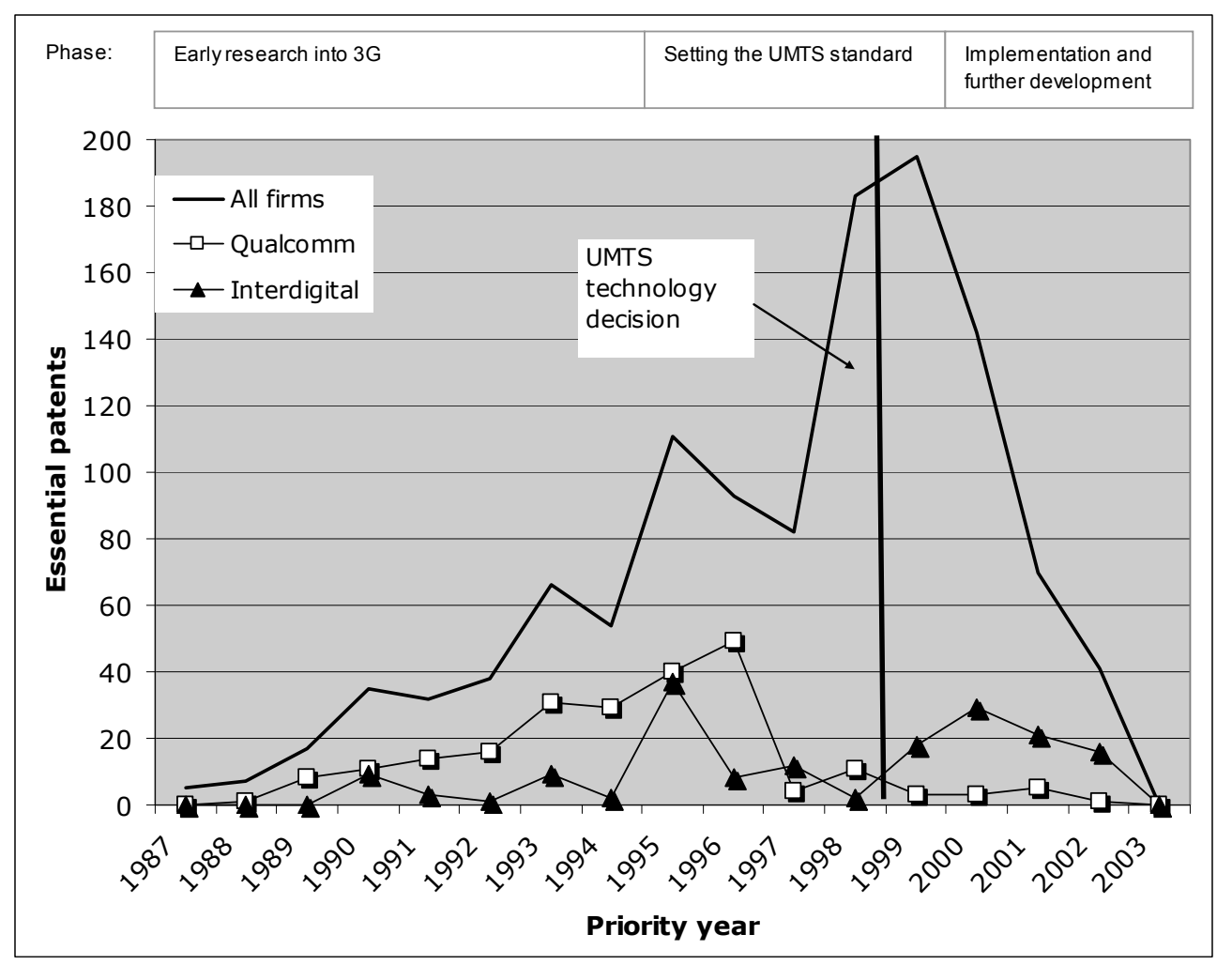

Figure 2: Timing of essential UMTS patents by leading IPR firms

Targeting. Another measure of strategic patenting would be if a firm's patenting is primarily focused at a particular standardization effort (here UMTS) rather than more broadly on mobile telephony or telecommunications. To consider this, we have compared their overall patent ownership in relevant mobile telecommunications categories with the UMTS essential patents that the firm owns. We have identified the IPC codes that covered $97 \%$ of our essential patent data set, but omitted those IPC classes not specific to telecommunications (covering general electrical computing inventions or musical instruments, for example) which would distort our data for firms that are diversified in more product markets. The remaining 11 IPC codes (five at the subclass level, six at the more detailed group level) still cover $85 \%$ of all patents essential to GSM, and therefore we consider these patent categories to be a good representation of inventions for mobile telecommunications.

For the 12 firms that rank highest on essential patent ownership (each holding more than 5 patents), we have identified all patents in these categories that were published by the EPO up to March 2005. The results are presented in Table 4, column (2). When we then look at the share of essential UMTS patents published at EPO - as shown in column (4) — then there are two clear outliers. Both InterDigital (93\%) and Asustek (92\%) disclose nearly all of their mobile telecom patents filed at EPO as UMTS essential patents, a strong indication that their patenting activity was specifically directed to inventions that would become implemented in UMTS. The third highest score is for Qualcomm, of which $22 \%$ of the patents in this field are essential to UMTS. For all other firms, the ratio is $10 \%$ or less. One explanation might be that of a firm's global innovations, only the patents relevant to European use (in this case GSM or UMTS) are patented in Europe. Therefore, we have also analyzed the essential patent in relation to the mobile telecommunications patents held in the U.S.. While this reduces the ratio for InterDigital, nonetheless both it and Asustek remain outliers. 


\begin{tabular}{|c|c|c|c|c|c|}
\hline Firm & $\begin{array}{r}\text { Unique essential } \\
\text { patents notified } \\
\text { at ETSI (1) }\end{array}$ & $\begin{array}{r}\text { All mobile telecom } \\
\text { related patents in } \\
E P O(2)\end{array}$ & $\begin{array}{r}\text { All mobile telecom } \\
\text { related patents in } \\
\text { USPTO (3) }\end{array}$ & $\begin{array}{r}\text { ETSI:EPO ratio } \\
\text { (4) }\end{array}$ & ETSI: USPTO ratio \\
\hline Nokia & 248 & 2,591 & 2,330 & $10 \%$ & $11 \%$ \\
\hline Ericsson & 244 & 2,386 & 3,672 & $10 \%$ & $7 \%$ \\
\hline Qualcomm & 228 & 1,047 & 1,079 & $22 \%$ & $21 \%$ \\
\hline InterDigital & 168 & 181 & 375 & $93 \%$ & $45 \%$ \\
\hline Samsung & 86 & 1,016 & 1,317 & $8 \%$ & $7 \%$ \\
\hline Motorola & 54 & 1,144 & 4,497 & $5 \%$ & $1 \%$ \\
\hline Philips & 45 & 1,493 & 1,535 & $3 \%$ & $3 \%$ \\
\hline Siemens & 38 & 2,590 & 1,719 & $1 \%$ & $2 \%$ \\
\hline Asustek & 23 & 25 & 17 & $92 \%$ & $\dagger 135 \%$ \\
\hline Alcatel & 20 & 2,027 & 1,780 & $1 \%$ & $1 \%$ \\
\hline Mitsubishi & 18 & 439 & 814 & $4 \%$ & $2 \%$ \\
\hline Nortel & 15 & 921 & 1,662 & $2 \%$ & $1 \%$ \\
\hline
\end{tabular}

Note: Ratio values larger than 0.20 are printed bold. Mobile telecom patents in (2) and (3) are patents in IPC categories G01S1, G01S5, H01Q21, H01Q3, H04B, H04J, H04K1, H04L, H04M, H04N1 or H04Q

(1) Notification filed at ETSI according our analysis based of ETSI SR 000314 V1.14.1 (2005-04)

(2) Patent filed at the EPO on or after 1 Jan. 1983 and published by 28 Feb 2005.

(3) Patent filed at the USPTO on or after 1 Jan. 1983 and published by 24 January 2006.

+ Asustek notified ETSI of 12 patents filed with EPO without an USPTO equivalent.

Table 4: Relative specialization in UMTS in relation to all mobile telecom patents, for the

12 most active firms.

Technological Diversity. A third difference between firms is the degree to which patents held by a particular firm relate to many different technical aspects of the standard or whether all patents relate to the same part of the standard. This is a measure of how diverse the overlap is between a firm's patent portfolio and the standard (cf. Granstrand et al, 1997).

To determine diversification, we studied the so-called standards deliverables for which the patents were deemed essential, as indicated in the notifications. The UMTS standard is made up of hundreds of deliverables, classified in 15 main series. These series cover different technical areas, such as radio aspects, (speech) codecs and security (see Table 5). Some series comprise (much) more patents than others, mostly because of differing nature of the technology. Overall, most of the essential patents that are in our database are indicated to be relevant for the 25 series ('radio aspects'; $38 \%$ of all patents); the 21 series ('requirements', $25 \%$ of all patents) and the 23 series ('technical realization', $13 \%$ of all patents). All other series comprise less than $10 \%$ of all patents. Our results indicate that Siemens and Nokia are most diversified, whereas the patents of firms like InterDigital, Motorola and Asustek are in one very narrow area (one or two series only).

\begin{tabular}{lccl}
\hline Firm & $\begin{array}{c}\text { Number of different } \\
\text { specification series in } \\
\text { which patents are } \\
\text { notified (1) }\end{array}$ & $\begin{array}{c}\text { Diversification } \\
\text { measurement } \\
\text { (corrected for } \\
\text { portfolio size) (2) }\end{array}$ & Main series (3) \\
\hline Nokia & 11 & 4.59 & $25,23,26,24,29$ \\
Ericsson & 0 & no data & no data \\
Qualcomm & 5 & 2.12 & $22,23,24,25$ \\
Interdigital & 1 & 0.45 & 21 \\
Samsung & 3 & 1.55 & 25 \\
Motorola & 1 & 0.57 & 21 \\
Philips & 2 & 1.20 & 25 \\
Siemens & 8 & 5.03 & 25,23 \\
Asustek & 1 & 0.72 & 25 \\
Alcatel & 2 & 1.51 & 25 \\
Mitsubishi & 3 & 2.35 & 25,26 \\
Nortel & 3 & 2.49 & 25 \\
\hline
\end{tabular}

\begin{tabular}{|l|}
\hline UMTS specifications series: \\
21: Requirements \\
22: Service aspects \\
23: Technical realization \\
24: Signaling protocols - user equipment \\
$\quad$ to network \\
25: Radio aspects \\
26: CODECs \\
27: Data \\
28: Signaling protocols \\
29: Signaling protocols - intra fixed \\
$\quad$ network \\
30: Program management \\
31: Subscriber Identity Module (SIM / \\
$\quad$ USIM) \\
32: OAM\&P and Charging \\
33: Security aspects \\
34: UE and (U)SIM test specifications \\
35: Security algorithms \\
\end{tabular}


Note 1: Column (2) is the total number of series in which a form owns patents (column 1) divided by the log of the size of the patent portfolio of that firm. This indicator can very between 0 (infinitive number of patents, once class) and 12,46 (one single patent in each of the 15 classes).

Note 2: ETSI and 3GPP use different coding for the classifications; for instance, ETSI deliverable TS 125.001 is equivalent to 3 GPP deliverable TS 25.001. Although the translation for some deliverables is complex (especially the older GSM, that are also coded by $3 G P P$ ), the concordance for UMTS deliverables is rather straightforward.

Note 3: InterDigital notified patents for UMTS but indicated them to be relevant for the 3GPP TS41 series - a series for GSM Release 4, not UMTS. We chose to count these declarations as part of the rather similar series 21 patents, because InterDigital officially notified these patents for UMTS

Table 5: Level of technological diversification

Comparing impact of IPR upon GSM and UMTS

Here we contrast the impact of IPR upon standardization between that reported for GSM (Iversen, 1999; Bekkers, 2001; Bekkers et al, 2002) and our analysis of that for UMTS.

IPR Proliferation. Overall, the rate of patents declared (at a comparable lag in standardization) grew $776 \%$ between GSM and UMTS (Table 6). However, we believe the UMTS patent count is understated, because several key firms provided non-specific (blanket) IPR claims to ETSI, and because in the interests of expediency we have not reconciled those patents declared at ARIB and ATIS against the ETSI list.

\begin{tabular}{|l|c|c|c|c|}
\hline & \multicolumn{2}{|c|}{ GSM } & \multicolumn{2}{c|}{ UMTS } \\
\hline & Beginning & End & Beginning & End \\
\hline Importance of patents & low & high & high & high \\
\hline ETSI patent policy & none & ETSI (1994) & unchanged & $\begin{array}{c}\text { largely } \\
\text { unchanged }\end{array}$ \\
\hline \# of firms holding patents & & 23 & & 72 \\
\hline \# of unique patents & & 140 & & $1,227 \dagger$ \\
\hline Maximum \# patents per firm & & 27 & & 248 \\
\hline Mean \# patents per firm & \multicolumn{3}{|l|}{6.1} & \multicolumn{2}{c|}{} \\
\hline
\end{tabular}

Patent count: for GSM as of 1996 (Bekkers et al 2002), for UMTS as of 2005 (ETSI 2005)

$\dagger$ Excludes patents only covered by blanket disclosures or disclosures outside ETSI

Table 6: Comparison of GSM and UMTS IPR

Beyond patent growth, we see two other key differences in the impact of IPR upon the GSM and UMTS standardization efforts. First, while the importance of IPR upon mobile telecommunications was not widely understood at the beginning of the GSM effort, at the end of that effort - and all throughout UMTS - many firms realised that patent rights were an important part of their mobile telecommunications strategies. Thus, the number of firms claiming IPR increased $217 \%$, and the mean number of patents per firm increased $175 \%$.

Second, the GSM standardization effort began without a formal IPR policy, but by the end of the standardization efforts ETSI worked out a policy reflecting a compromise between suppliers and operators. That same policy (with only minor changes) was in effect throughout UMTS.

However, despite these changes, in neither case did the patent policy achieve the goals of either the equipment buyers (operators) or prospective new suppliers. As noted in the previous section, some of this was due to inherent limitations between voluntary standardization and the ability of firms to opt-out of ETSI participation. However, we would argue that this also reflected learning effects by individual suppliers that found ways to maximize their IPR leverage within the existing ETSI policy.

Patenting Strategies. While the mean patents per firm increased, the median decreased (from 5 to 3), reflecting the skewness of the patent distribution. The share of patents held by the top 16 patent holders (averaged across both efforts) are shown in Figure 3. 


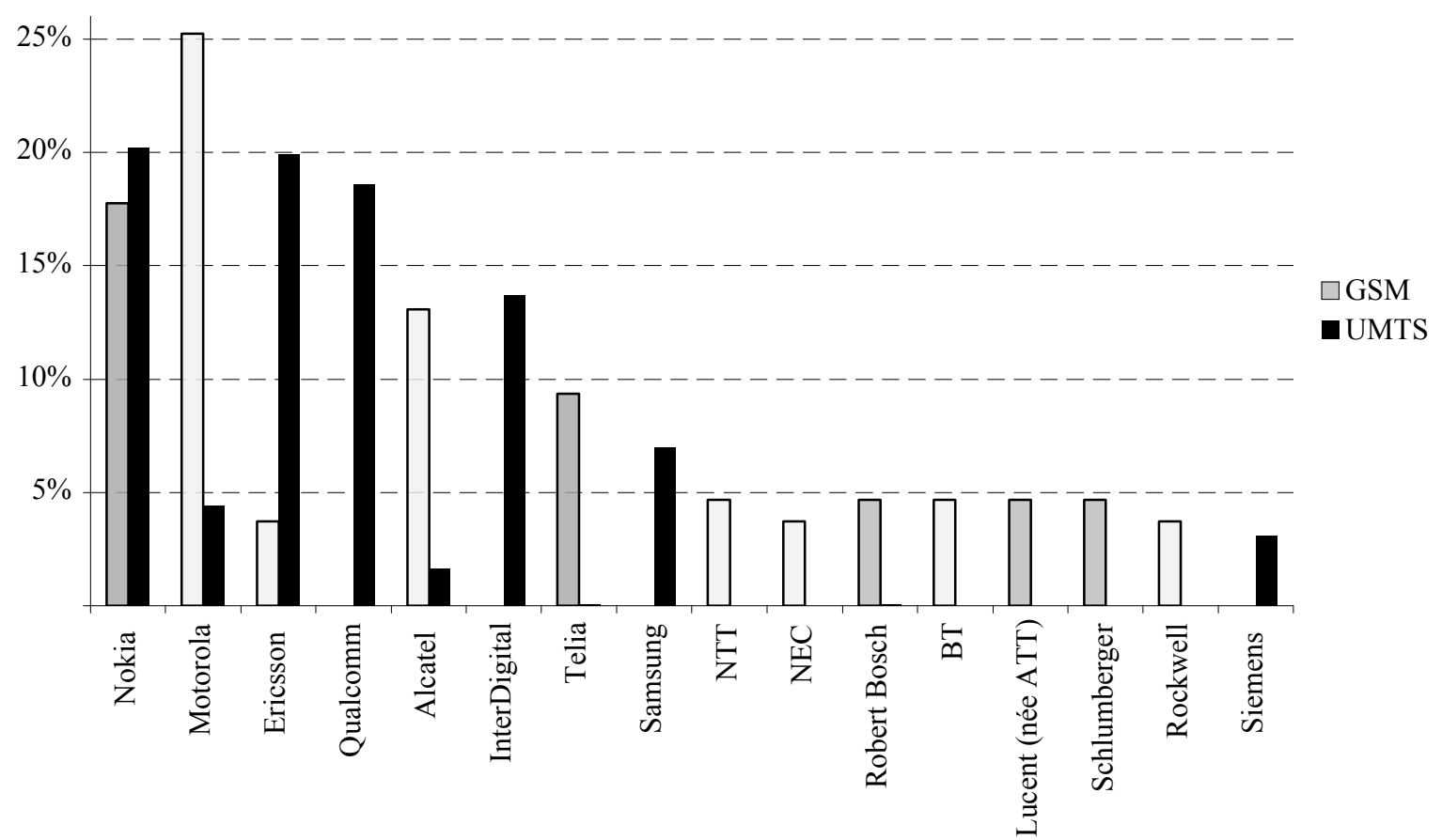

Notes:

- Lucent offered only a 'blanket' ESTI disclosure and thus the total patents are unknown

- $\quad$ NEC and NTT used a 'blanket' disclosure at ETSI, but even if ARIB (2000) patents were added to ETSI totals, would hold less than $1.5 \%$ of the global total.

Figure 3: Ratio of GSM and UMTS patent disclosures by leading firms

We would classify the dynamics of firm patent strategies into three categories:

- Increased patent activity. Ericsson and Nokia - the two European suppliers most centrally involved in both the GSM and UMTS standardization - dramatically increased their patent activity. As noted earlier, many of these patents were filed at the same time the UMTS standard was becoming finalised.

- New entrants. Four firms held significant UMTS patent portfolios but were not represented in ETSI disclosures by the 1996 cut-off date of Bekkers et al (2002). Siemens was involved in GSM standardization while Samsung was not; by 2005, both firms had notified a relative small number of 'GSM'-only patents (ETSI 2005). Qualcomm and InterDigital are the 3rd and 4th largest holders of UMTS patents, holding large portfolios of UMTS-related patents filed before UMTS Release 99, but also have since claimed hundreds of raw GSM-related patents. In the mid-1990s, InterDigital sued GSM mobile phone makers seeking royalties on terminal sales (Bekkers, 2001: 326). ${ }^{8}$ Meanwhile, Qualcomm's assertion of its GSM patents (in the period 2005-2007) seemed limited to those firms with which it had CDMA- or UMTS-related patent disputes.

- Reduced or terminated patenting activity. Three operators (Telia, NTT, BT) held 19\% of GSM patents, but (together with former NTT subsidiary NTT DoCoMo) held less than $2 \%$ of the UMTS patents. ${ }^{9}$ Suppliers Bosch and (by inference from ARIB filings) NEC greatly reduced their patent disclosures; two other significant GSM patent holders (Schlumberger, Rockwell) did not declare any UMTS patents.

8 The patents of InterDigital Communications Corporation are held by its subsidiary InterDigital Technology Corp., which in ETSI (2005) filed more than 200 raw disclosures for GSM alone. However, this patent count cannot be directly compared to the totals shown in Figure 3, because it does not remove duplicate disclosures and is more than 9 year after the cutoff date chosen by Bekkers et al (2002).

9 Telia disclosed 1 unique patent to ETSI and BT none, while DoCoMo and NTT disclosed 24 raw patents together to ARIB (2000). As with the discussion of InterDigital GSM patents above, the raw patent count is an upper bound of the unique patents. 
However, the number of UMTS patent claims by Lucent (ATT's former manufacturing subsidiary) could not be determined from its blanket disclosures.

\section{Assessing the ETSI IPR policy}

After analyzing the ownership of UMTS patents, we now consider how effective is the ETSI IPR policy? To answer this question, we list some of the possible problems and then review ETSI's own review of its policy.

\section{Claimed weaknesses}

Here is a summary of the key problems identified for ETSI and similar IPR policies:

Disclosure, notification and claiming. The cornerstone of the ETSI IPR process is disclosure of IPRs essential to a standard, and RAND licensing of those IPRs. The process fails if firms do not provide notifications which cannot be compelled of non-members — or provide incomplete disclosures (such as blanket claims). The vague notification requirement does not assure a well-structured and reliable ETSI IPR database, and ETSI lacks strong enforcement mechanisms even for its members.

A well known example of IPR disclosure in standardization is the Rambus case, in which Rambus was accused of not disclosing its patents during JEDEC standardization of a new memory technology (Tansey et al, 2005). A series of conflicting rulings from US Federal courts and then the Federal Trade Commission left ambiguous as to what actions would be considered legal in the future (Iversen et al, 2006). However, the Rambus case - like the early case of Dell and the LocalBus standard (Bekkers \& Liotard, 1999) shows that firms risk legal action if they under-disclose their IPR.

If anything, the legal precedents and ETSI policy encourage over-claiming, as with the obligation to "draw the attention of ETSI to any of that member's IPR which might be essential if that proposal is adopted' (ETSI, 2006). Even the most conscientious firm may have difficulty avoiding over-claiming, either due to timing (a disclosure early in standardization often proves obsolete once the standard is finalized) or due to the degree of overlap (since confirming a claim may take significant labour-hours of a skilled engineer).

However, some firms may systematically over-claim patents to increase the perceived importance of their patent portfolio and thus their share of royalties. The more patents a firm claims, the harder it is for an opponent to invalidate (or prove non-essential) the entire portfolio. In fact, some firms have been accused of massive overclaiming. One such firm is InterDigital, which told shareholders: 'We cannot assure that the validity of our patents will be maintained or that any of the key patents will be determined to be applicable to any $2 \mathrm{G}$ or $3 \mathrm{G}$ product' (InterDigital 2006: 22).

Technology Selection. Formal standardization is assumed to seek technologically optimal solutions, but the process often reflects the cumulative self-interest of participants due to weak feedback mechanism to limit excesses of self-interest. This is equally true for IPR issues. Bekkers (2007) argues that SSO participants allow others to move trivial patents into standards as long as they are allowed to put their own trivial patents into the standard. Standards decisions may also be made due to political pressure, as when Qualcomm withheld IPR licenses to win changes to the UMTS standard to make it easier for it to build multi-standard chipsets (Bekkers, 2001). Some technical committees may even include technologies without being aware of patents, because the patents are held by non-members, by members not present in the TC, or even by members present in the TC that are unaware of their own complete IP portfolios.

Licensing Terms and Conditions. While the ETSI IPR policy requires members to license essential IPR under (F)RAND conditions, there are many complaints about 'unFRANDly' terms. The RAND clause is both vaguely defined and hard to implement:

- Comparability. Because there are many variations in the terms of contracts - volume discounts, crosslicensing, licensing of non-essential IPR - no two contracts are exactly alike and thus it's hard to determine if given terms are 'fair' and 'non-discriminatory' (Updegrove 2006);

- Transparency. It's impossible to compare contracts if they are kept secret via Non-Disclosure Agreements. Without access to contracts, it's impossible to compare and thus enforce FRAND conditions;

- Divergent Opinions. Different parties (integrated firm, IP-owning firm, implementing firm) have different opinions about 'fair' and 'reasonable.' For example, should licensing consider the cumulative license fee for all patents, or only the individual value of one patent?

Cumulative effects, including royalty stacking and transaction costs. Even if individual patent fees are reasonable, the result of having many patent royalties and holders is that license fees are "stacked", possibly to the extent that the cumulative fee is prohibitive (Lemley \& Shapiro, 2007). This problem is exacerbated for multi- 
function, multi-technology products (like a phone with a camera and music player) which stack the royalties for each function upon the other.

Having many IPR holders also increases transaction costs of negotiating licenses. Patent pools have been proposed to reduce licensing cost transaction costs and complexity, while others see the pools as an opportunity to cap the cumulative license fee (Iversen, et al, 2006).

Transparency of essential patents. The ETSI IPR policy is premised on a self-certification of essentiality, but as noted above there are incentives both to over-notify and under-notify. Without any independent assessment of essentiality, there is a great uncertainty over which IPR is actually essential — uncertainty that tends to be resolved through expensive litigation.

Transparency and predictability of license terms. Through various phases of standards development and implementation, implementers face uncertainty about the pricing of IPR royalties. Such uncertainty raises the risks for planning, particularly early in the process.

Third party IPR holders. Non ETSI members that claim to own essential IPR pose specific challenges to the IPR policy. They are not bound to the ETSI policy, and thus have no obligation to disclose their IPR, and no sanctions for non disclosure. In particular, licensing-only companies (without the need for cross-licensing) have a strong power for hold up (cf. Lemley \& Shapiro, 2007).

\section{ETSI's review of its IPR policy (2005-2006)}

Within ETSI, some members have criticized the IPR policy as being weak and ineffective. For example, twenty of the largest operators and suppliers in the field of mobile telecommunications (Alcatel, BT, Vodafone et al, 2005) listed the following concerns:

- Deferred IPR declarations lead to agreement on standards without members knowing all IPR involved.

- 'RAND' is not sufficient. The lack of definition of commercial terms has resulted in unsustainable demands. Royalty obligations are inaccessible for an evaluation of whether they are fair, reasonable and non-discriminatory.

- Cumulative patent royalties ('patent stacking') can raise the license burden to an extent unbearable to our industry.

- Lack of IPR transparency through unfiltered publishing of thousands of patent declarations, further compounded by bundling of patents in portfolios.

- Lack of active IPR management. SSOs generally do not actively manage IPR: no essentiality check for patents declared, no IPR intelligence, no IPR issue resolution, no policing of IPR rules, no sanctioning of non-compliance.

In response to these concerns, in 2005 ETSI established an ad hoc IPR Review group, to provide advice to the ETSI General Assembly. This IPR group had three (closed) workshops, with dozens of members participating. The workshop identified a wide range of reforms, ranging from patent landscaping (identifying possible IPR prior to standards selection) and patent pools, to more drastic fixes, such as mandatory ex ante licensing. The ad hoc group finished its work in November 2006. Outside sources indicate that consensus could not be reached around most of these proposals (see ATIS, 2006).

Not surprisingly, then, the report and advice of the IPR review ad hoc group included only incremental changes: most of its 16 recommendations relate to clarifications and smaller issues for the IPR policy and related ETSI documents. More substantial activities, such as collective licensing arrangements, patent pools and IPR landscaping would be considered as 'an activity outside of ETSI'. Many issues were deferred with the recommendation to create a permanent 'IPR Committee'. Further clarification of RAND and addressing the problems of cumulative licensing were among the issues forwarded to this new IPR Committee (ETSI, 2006).

Why did the final recommendations make only minor changes to the IPR policy? Is it because there are not serious problems, or because differences among stakeholders prevented reaching consensus on the desired changes? This is a paramount question, because if the ETSI IPR policy has major problems, then the policies of many SSOs might also need to be revised. In fact, responding to the ETSI discussion, other standards bodies such as ATIS began considering reforms as well (see ATIS, 2006).

\section{Discussion}

Our study of UMTS patenting makes two contributions to understanding the difficulties that standardization bodies have today in managing the impact of IPR upon standards. First, we show the sources of patent proliferation. Second, we discuss the limits of potential policy solutions. 
The sources of UMTS patent proliferation have often been ascribed to IPR-focused companies outside the ETSI process, particularly Qualcomm and InterDigital. However, our study shows that the largest number of patents are held by two firms (Nokia and Ericsson) centrally involved in the UMTS standardization, and the timing of their patenting suggests that they used their knowledge of the standard's development for anticipatory patenting further contributing to patent proliferation.

Still, a cozy oligopoly of four main UMTS patent holders might have produced a manageable IPR regime comparable that to the five major holders of GSM patents. However, the number of firms claiming at least a one patent has grown threefold, increasing the risk of holdup, transaction costs and royalty stacking for firms implementing the newer standard. This uncertainty is magnified by the self-determination of essentiality: on the one hand, it's virtually impossible to determine how many of the 1,227 patents are actually necessary to implement UMTS, while other parties fail to provide an itemized list of essential patents.

To address such problems, ETSI developed an IPR policy, which (unlike for GSM) was in force during the entire UMTS development process. However, that policy has proven unable to limit the problems due to the proliferation of patent claims and patent holders. And ETSI's 2005-2006 ad hoc study shows that while the problems are well known, an industrywide standardization body faces inherent difficulties in building IPR policy consensus among divergent stakeholder interests - in this case, operators, manufacturers and licensing companies.

Future research should consider the issues of patent proliferation under different policy regimes. For example, patent pools have been assembled for consumer electronics standards such as MPEG-4, HD DVD and Blu-ray. It's an open empirical question as to whether these efforts been more successful in managing patent proliferation, licensing and transaction costs — and, if so, whether it has been through stronger mechanisms for aligning participant interests, or through controls that limit the number of members firms (and thus patent claimants).

\section{References}

Alcatel, BT, Deutsche Telekom, France Telecom, Hutchison Europe Telecommunications S.a.r.l., KPN, Orange, Portugal Telecom, Research in Motion, SFR, Sun Microsystems, Swisscom SA, TDC, Telekom Austria, Telecom Italia, Telefonica, Telenor, TeliaSonera AB, T-Mobile, Vodafone Group (2005): "IPR committee to work on IPR reform in standards," ETSI 46th General Assembly meeting, Nice, 22-23 November 2005

ARIB (2000). "List of Essential Property Rights (IPRs) for ARIB STD-T63: IMT-2000 DS-CDMA system," Association of Radio Industries and Businesses, Tokyo.

ATIS. (2005). “ATIS Patent Information", Alliance for Telecommunications Industry Solutions, accessed November 2005, URL: http://www.atis.org/tc/patpolicy.asp

ATIS (2006). “ATIS Intellectual Property Rights Policy Task Force,” Alliance for Telecommunications Industry Solutions, accessed June 2007, URL: http://ftp.tiaonline.org/TechCommittee/Working/2006November03Teleconference/TC_20061103015_Staff_ATIS_IPR_Review.pdf

Bekkers, R. (2001). Mobile telecommunications standards: GSM, UMTS, TETRA, and ERMES. Artech House, Boston.

Bekkers, R. (2007). Patent drag and stacking IPR fees - Are IPR policies of standards bodies failing or should we better address excessive technology inclusion? Position paper for the High-Level Workshop on standardization, IP licensing, and antitrust, TILEC, Chateau du Lac, Brussel, 18 January 2006. Conference program.

Bekkers, R. N. A., \& Liotard, I. (1999). The tense relation between mobile telecommunications standards and IPR. European Intellectual Property Review 21 (3), 110-126.

Bekkers, R., Verspagen, B. \& Smits, J. (2002). Intellectual property rights and standardization: The case of GSM. Telecommunications Policy 26 (3-4), 171-188.

Buitenwerf, Evert (1994). Considerations on network interfaces for third generation mobiletelecommunication systems. Proceedings of the 5th IEEE International Symposium on Personal, Indoor and Mobile Radio Communications, 1994. Wireless Networks - Catching the Mobile Future, Vol 3., pp. 857-862.

ETSI. )1994). "ETSI IPR Policy," Annex 6 of ETSI Rules of Procedure, European Telecommunications Standards Institute, Sophia Antipolis, France.

ETSI. (2005). "Intellectual Property Rights (IPRs); Essential, or potentially Essential, IPRs notified to ETSI in respect of ETSI standards," ETSI SR 000314 V1.14.1 (2005-04), European Telecommunications Standards Institute, Sophia Antipolis, France. 
ETSI. (2006). "ETSI IPR Policy,” Annex 6 of ETSI Rules of Procedure, European Telecommunications Standards Institute, Sophia Antipolis, France, November 22, URL: http://www.etsi.org/legal/documents/ETSI_IPRPolicy.pdf, accessed 25 May 2007.

Garrard, Garry A. (1998). Cellular Communications: Worldwide Market Development, Artech House, Boston.

Goodman, David J. \& Myers, Robert A. (2005). “3G Cellular Standards and Patents," Proceedings of 2005 IEEE Wireless Communications and Networking Conference,, June 13-16, pp. 415-420.

Granstrand, Ove; Patel, P.; Pavitt, Keith.(1997). "Multi-technology corporations: Why they have 'distributed' rather than 'distinctive' core competencies." California Management Review, 39(4), 8-25.

Hillebrand, Friedhelm, ed. (2003). GSM and UMTS: the creation of global mobile communication: Wiley, Chichester, England.

Interdigital (2006). 2006 Annual report. King of Prussia, PA.

Iversen, Eric J. (1999). "Standardization and Intellectual Property Rights: ETSI's controversial search for new IPR procedures," Proceedings of the 1st IEEE Conference on Standardisation and Innovation in Information Technology, Aachen, Germany, September 15-17: 55-63.

Iversen, Eric, Rudi Bekkers \& Knut Blind (2006). Emerging coordination mechanisms for multi-party IPR holders: linking research with standardization. Paper presented at the DIME Conference on Intellectual Property Rights for Business and Society, September 14-15 2006, London.

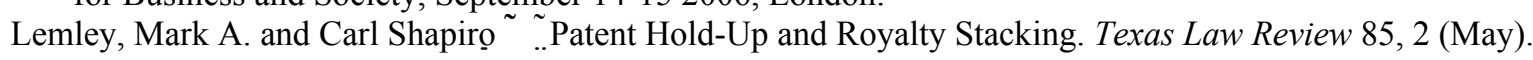

Tansey, Richard, Mark Neal, and Ray Carroll. 2005. “Get Rich, or Die Trying”: Lessons from Rambus' High-Risk Predatory Litigation in the Semiconductor Industry, Industry and Innovation 12, 1 (March): 93-115.

PA Consulting Group, (2002). "Essential patent rights in 3G wireless will win or lose companies millions," press release, September 11, URL: http://www.paconsulting.com/news/press_release/2002/pr_20020911.htm

PlatformWCDMA (2004). "PlatformWCDMA Announces Plan for Launch of the W-CDMA Patent Licensing Program for 3G systems based on the W-CDMA technology," March 24, URL: http://www.3glicensing.com/articles/2003226d.pdf

Updegrove, Andrew. (2006). Microsoft, Adobe and the Murky World of "RAND", ConsortiumInfo.org Standards Blog, June 7, 2006, http://www.consortiuminfo.org/standardsblog/article.php?story=20060607091049902

West, Joel (2006) “Does Appropriability Enable or Retard Open Innovation?” In Henry Chesbrough, Wim Vanhaverbeke, and Joel West, eds., Open Innovation: Researching a New Paradigm, Oxford University Press, Oxford, pp. 109-133. 